\title{
७MONÇÕES
}

\section{A Formação da agenda e a Seleção da alternativa para a participação do Brasil na instalação da Sociedade Moçambicana de Medicamentos (SMM)}

\author{
The agenda setting and the alternative specification for the \\ Brazil's participation in ihe installation of the Mozambican Society \\ of Medicines (MSM)
}

La formación de la agenda y la selección de la alternativa para la participación de Brasil en la instalación de la Sociedad Mozambicana de Medicamentos (SMM)

\author{
Michelle Silva Santos \\ Mestre em Ciência Política pela Universidade Federal de Goiás (UFG). \\ Goiânia, Goiás, Brasil. \\ E-mail: santosmichelle1784@gmail.com \\ Orcid: https://orcid.org/0000-0001-6761-710X
}

\begin{abstract}
Andréa Freire de Lucena
Professora associada, Universidade Federal de Goiás (UFG). Goiânia, Goiás, Brasil.

E-mail: andflucena@gmail.com

Orcid: https://orcid.org/0000-0003-2984-3688
\end{abstract}

Resumo: $\mathrm{O}$ artigo tem por objetivo apresentar o processo de formação de agenda e seleção de alternativa que deu origem a participação do Brasil na instalação da Sociedade Moçambicana de Medicamentos (SMM). A análise foi baseada no Modelo dos Fluxos Múltiplos, de John Kingdon (1984). Embora este seja um modelo tradicionalmente utilizado para análise de políticas de âmbito nacional, ele foi empregado neste estudo devido a sua gama de variáveis, que permitem uma análise consistente dos aspectos domésticos e internacionais que influenciaram na condução dessa política. $\mathrm{O}$ artigo se propõe também a apresentar o Modelo dos Fluxos Múltiplos como possibilidade metodológica para analisar a formação da agenda e seleção de alternativa em ações de cooperação internacional. As fontes de dados utilizadas foram documentos dos governos brasileiro e moçambicano, que foram compreendidos por meio da análise de conteúdo. Como resultado, o artigo identificou os fatores que influenciaram na condução dos fluxos que deram origem à parceria entre Brasil e Moçambique para a instalação da SMM. De modo mais específico, concluiu-se que a janela de oportunidade que deu origem à política em questão foi aberta pelo fluxo da política brasileira.

Palavras-chave: Cooperação internacional; Brasil; Moçambique. 
Abstract: The article aims to present the processes of agenda setting and alternative specification that gave rise to Brazil's participation in the installation of the Mozambican Society of Medicines, based on the Multiple Streams Framework (MSF), by John Kingdon (1984). The model has traditionally been used for the analysis of national policies and it was used due to its range of variables that allows a consistent analysis of the domestic and international aspects that influenced the conduct of this policy. The article also proposes to present the Multiple Streams Framework as a methodological possibility to analyze the formation of the agenda and the selection of alternative in international cooperation actions. The main data sources used were documents from the Brazilian and Mozambican governments, which were understood through content analysis. As a result, the article identified the factors that influenced the conduct of the flows that gave rise to the partnership between Brazil and Mozambique for the installation of the SMM. More specifically, it was concluded that the window of opportunity that gave rise to the policy in question was opened by the flow of Brazilian politics.

Keywords: International cooperation; Brazil; Mozambique.

Resumen:El artículo tiene como objetivo presentar el proceso de establecimiento de la agenda y selección de alternativa que dieron lugar a la participación de Brasil en el establecimiento de la Sociedad de Medicamentos de Mozambique (SMM). El análisis se basó en el modelo de flujos múltiples de John Kingdon (1984). El modelo se ha utilizado tradicionalmente para analizar las políticas nacionales y fue utilizado debido a su gama de variables que permite un análisis coherente de los aspectos nacionales e internacionales que han influido en la conducción de esta política. El artículo también propone presentar el Modelo de Flujos Múltiples como posibilidad metodológica para analizar la formación de la agenda y selección de alternativa en acciones de cooperación internacional. Las fuentes de datos utilizadas fueron documentos de los gobiernos de Brasil y Mozambique, que se entendieron a través del análisis de contenido. Como resultado, el artículo identificó los factores que influyeron en la conducción de los flujos que dieron lugar a la asociación entre Brasil y Mozambique para la instalación del SMM. Más específicamente, se concluyó que la ventana de oportunidad que dio origen a la política en cuestión fue abierta por el flujo de la política brasileña.

Palabras clave: Cooperación internacional; Brasil; Mozambique.

Recebido em 21/02/2020.

Aceito em $11 / 04 / 2020$. 


\section{INTRODUÇÃO}

As ações de cooperação internacional na área do HIV/AIDS, no Brasil, começaram na década de 1990, no governo Fernando Henrique Cardoso (FHC), como uma parte importante da política externa do país, e foram reforçadas durante o governo de Luís Inácio Lula da Silva. O Brasil, desde os anos 2000, começou a oferecer transferência de tecnologia para produção de antirretrovirais em outros países em desenvolvimento (BRASIL, 2002). Em 2002, teve início, no âmbito do Ministério da Saúde, o Programa de Cooperação Internacional para Ações de Prevenção e Controle do HIV/AIDS para outros Países em Desenvolvimento. Esse programa tinha por objetivo financiar a implantação de 10 projetos pilotos, com valor anual de $\mathrm{R} \$ 250$ mil reais cada, que seriam realizados por meio de assistência técnica, doação de medicamentos antirretrovirais produzidos por laboratórios públicos brasileiros e capacitação de recursos humanos. Foi no âmbito desse projeto que o Brasil firmou com Moçambique suas primeiras parcerias relativas ao HIV/AIDS (FOLLÉR, 2013).

A Sociedade Moçambicana de Medicamentos, ou SMM, é considerada por alguns como o mais emblemático projeto de cooperação internacional brasileiro na África ${ }^{1}$ e como símbolo da dificuldade brasileira de realizar projetos de cooperação internacional de grande porte (ROSSI, 2013). No entanto, o mais longo projeto de cooperação do governo brasileiro na África, e o mais caro - com custo estimado em $\mathrm{R} \$ 40$ milhões - apesar de ter, inicialmente, como principal objetivo a produção de antirretrovirais (ARVs), não produz mais esse tipo de medicamento. O antirretroviral Nevirapina, cuja tecnologia para produção foi transferida, é hoje ultrapassado e, por isso, sua produção foi suspensa. Os planos eram que a fábrica produzisse, além da Nevirapina, outros antirretrovirais, que também já estão ultrapassados (ROSSI, 2017).

O projeto também envolveu a transferência de tecnologia para produção de outros medicamentos não ARVs e hoje, como primeira e única indústria farmacêutica pública no país, a SMM produz soluções injetáveis e, ainda, sólidos orais indicados para o tratamento, por

\footnotetext{
${ }^{1} \mathrm{~A}$ cooperação para a instalação da fábrica também contemplou a transferência de tecnologia, de técnicas de gestão e de técnicas laboratoriais para capacitar o corpo técnico e gerencial moçambicano (COMITIVA..., 2020).
} 
exemplo, de diabetes e pressão alta. Além desses, a fábrica possui uma série de outros medicamentos em fase de desenvolvimento. Os medicamentos produzidos pela SMM abastecem o Serviço Nacional de Saúde do país ${ }^{2}$. Mas, como um projeto tão caro e controverso foi alçado à agenda política brasileira? Ainda, por que o governo brasileiro decidiu que a solução para resolver o problema de acesso aos ARVs em Moçambique seria por meio da instalação de uma fábrica que os produzisse?

É comum que as pessoas se perguntem como o governo está conduzindo determinada política, mas, apesar dos questionamentos, é menos usual que se pergunte como um problema foi definido como importante e como os governantes decidiram selecionar determinada solução para enfrentá-lo. Foi buscando respostas como essas que John Kingdon (1984) desenvolveu o Modelo dos Fluxos Múltiplos (Multiple Streams Model). O modelo busca avaliar, com base no fluxo dos problemas, da política e das alternativas, por que algumas questões ascendem à agenda governamental enquanto outras são negligenciadas.

Compartilha-se a compreensão de Sanches et al. (2006) de que as políticas interna e externa fazem parte de um mesmo processo decisório. De acordo com as autoras, a política externa não se diferencia das demais políticas públicas e o processo decisório da política interna e externa pode estar sujeito à mesma metodologia de análise das fases de políticas públicas. Nesse sentido, o artigo propõe o uso do Modelo dos Fluxos Múltiplos para análise do processo decisório de ações de Cooperação Internacional quando houver o interesse de compreendê-lo a partir dos variados aspectos que influenciam a sua formação.

O objetivo do artigo consiste em compreender como a parceria Brasil-Moçambique para a instalação da SMM ascendeu como prioridade na agenda do governo brasileiro e como se deu a seleção da alternativa para essa política. A pesquisa é qualitativa e documental e fez uso da análise de conteúdo principalmente dos atos internacionais firmados entre Brasil e Moçambique no processo que deu origem à parceria para a instalação da SMM.

${ }^{2}$ Informações fornecidas pela SMM, por e-mail institucional em julho de 2020. 


\section{O MODELO DOS FLUXOS MÚLTIPLOS}

John Kingdon em seu livro Agendas, Alternatives, and Public Policies, de 1984, buscou avaliar porque algumas questões ascendem à agenda governamental, enquanto outras são negligenciadas, e porque algumas alternativas para tais questões são levadas em consideração, enquanto outras são ignoradas. Para ele, boa parte das respostas para estes questionamentos está relacionada aos atores envolvidos no processo e ao processo em si. Kingdon (1984) reconheceu a existência de três fluxos nesse processo, o fluxo dos problemas, das alternativas e das políticas.

Seu estudo se concentra em duas fases da política pública, a formação da agenda e a seleção da alternativa. O processo de formação de agenda destaca os acontecimentos que fizeram com que determinado tema alcançasse a agenda governamental. No que se refere à formação de agenda (agenda setting), Kingdon (1984) se propõe responder como a agenda governamental é construída a partir da análise do fluxo dos problemas e das políticas. No processo de seleção de alternativa, o autor apresenta a grande gama de alternativas possíveis diante daquelas que são de fato escolhidas.

No fluxo dos problemas, o modelo tenta analisar por que alguns problemas ocupam a atenção governamental mais do que outros. A resposta para tal questionamento reside no modo pelo qual determinada situação passa a ser percebida e como começa a ser reconhecida como problema. As situações se tornam problemas e despertam a necessidade de ação por meio de mecanismos como indicadores e eventos de destaque (focusing events). Quando os indicadores apontam para uma situação, ela pode ser percebida como um problema pelos formuladores de políticas. Os indicadores não determinam a existência de um problema, mas contribuem, principalmente, quando revelam dados quantitativos que mostram a existência de uma situação que precisa de atenção. Assim, os indicadores servem para avaliar a magnitude de uma situação e seus níveis podem chamar a atenção das autoridades (KINGDON, 1984).

Um evento de destaque, como um desastre ou uma crise, chama mais atenção para algumas condições do que para outras. Os eventos de destaque entram em cena, pois, muitas 
vezes, um problema não é determinado por meio de indicadores, mas sim por meio de eventos como crises e desastres que irão concentrar a atenção em determinado assunto. Embora tais eventos não possam por si só levar um assunto à agenda, eles podem reforçar a percepção preexistente de um problema. Kingdon (1984) explica que esses eventos podem perder o efeito se não houver uma indicação mais precisa de que há um problema, uma percepção pré-existente ou uma combinação desse evento com outros similares.

As alternativas de políticas públicas não surgem aos pares com os problemas. $\mathrm{Na}$ seleção da alternativa pelo modelo dos fluxos múltiplos, as ideias tecnicamente viáveis, com custos toleráveis, com valores compartilhados e com aceitação do público em geral e receptividade dos formuladores de política sobrevivem. A seleção da alternativa para um dado problema, para Kingdon (1984), é construída por meio da influência dos participantes ocultos no processo e, também, a partir do fluxo das políticas (policy stream). Os participantes ocultos, organizados em comunidades de especialistas, influenciariam a especificação da alternativa por meio da produção de propostas e soluções para determinados problemas. Eles atuam, por exemplo, no planejamento e na avaliação das políticas.

Os participantes ocultos de áreas específicas tendem a formar comunidades especializadas. Haveria, por exemplo, uma comunidade de especialistas na área da saúde, onde haveria pessoas localizadas em áreas ainda mais específicas, mas todos ligados à saúde. A aproximação nessas comunidades torna as propostas dos participantes conhecidas dos demais membros. As ideias são difundidas por meio de conversas, almoços etc. Assim, ocorre o compartilhamento, as críticas, o aprimoramento e a revisão das ideias (KINGDON, 1984).

No fluxo das alternativas, Kingdon (1984) percebe a seleção de alternativa de modo semelhante ao modelo garbage can de Cohen, March e Olsen (1972). Para eles, as escolhas políticas eram feitas como se as alternativas estivessem em uma lata de lixo, ou seja, as respostas não eram criadas conforme as demandas. As respostas dadas eram as disponíveis no momento, mesmo não sendo as mais adequadas para determinado problema. Kingdon (1984), partindo do mesmo pressuposto, analisa o modo como as alternativas são selecionadas fazendo uma analogia com a seleção natural biológica. Assim, as alternativas seriam geradas como se estivessem flutuando no caldo primordial da política, onde flutuariam 
muitas ideias que poderiam se encontrar formando combinações e recombinações. Desse modo, as origens das políticas seriam um tanto obscuras e difíceis de prever e de decifrar.

Por meio da análise do fluxo da política também se pode compreender a alta ou baixa importância que é dada a um tema pelo governo. Para Kingdon (1984), o fluxo da politica possui regras próprias e, por isso, flui independente do reconhecimento dos problemas ou do desenvolvimento de propostas de alternativas para as políticas públicas. Nele, os protagonistas são os atores visíveis, como o presidente, os ministros, os membros do congresso e a mídia. Os fatores que afetam esse fluxo são o clima ou humor nacional (national mood), a ação de grupos e forças políticas organizadas, a distribuição partidária ou ideológica do congresso e as mudanças dentro do governo, principalmente as trazidas por novas eleições.

Kingdon (1984) defende que cada um dos fluxos apresentados por ele - dos problemas, das alternativas e das políticas - são independentes. Cada um é definido e reconhecido conforme suas próprias características. Em determinadas circunstâncias, os três fluxos são reunidos e é então gerada uma oportunidade de mudança na agenda. A agenda governamental se refere aos temas que recebem atenção dos governantes durante um determinado período e a agenda de decisão se refere aos assuntos cujas decisões para resolução já estão em curso. Há momentos em que os fluxos se encaixam parcialmente, mas quando há a união completa dos três (problemas, alternativas e políticas), a chance do tema da agenda governamental se fixar na agenda decisória aumenta drasticamente (KINGDON, 1984).

As janelas de oportunidade (policy windows) são as circunstâncias que possibilitam a convergência dos três fluxos. Uma janela aberta é uma oportunidade para empreendedores políticos lançarem as soluções que defendem ou chamarem a atenção para problemas específicos. Tais empreendedores mantêm sempre soluções e problemas prontos à espera de uma janela de oportunidade. As janelas podem ser abertas por meio do fluxo dos problemas ou das políticas, assim, há janelas de problemas e janelas de políticas. Quando um novo problema surge, ele cria a oportunidade de se utilizar uma alternativa ou solução (KINGDON, 1984). 


\section{FORMAÇÃO DE AGENDA E A SELEÇÃO DA ALTERNATIVA}

Para que se possa compreender como a agenda governamental para a participação do Brasil na instalação da Sociedade Moçambicana de Medicamentos (SMM) foi estabelecida, de acordo com Kingdon (1984), é necessário considerar a ação do fluxo dos problemas, do fluxo da política e a ação dos participantes visíveis. Importante ressaltar que, para os fins do artigo, considerou-se que a agenda para o tema começou a ser formada em novembro de 2003, quando, na visita do presidente Luiz Inácio Lula da Silva a Moçambique, foi anunciada a intenção brasileira de participar da instalação da SMM. Além do protocolo de intenções para a instalação da SMM, foi firmado um memorando entre os países para a implantação do "Projeto de Assistência de Prevenção ao HIV/AIDS", que previa a doação de antirretrovirais genéricos do Brasil para Moçambique.

Esses dois documentos marcam a formação da agenda, pois são os primeiros atos relacionados à parceria estabelecida entre Brasil e Moçambique para acesso aos antirretrovirais (ARVs). Portanto, a visita do presidente Lula a Moçambique em novembro de 2003 é o momento em que o Brasil, reconhecendo o problema da falta de acesso aos ARV em Moçambique, passou a considerar que deveria fazer algo a respeito.

\section{Fluxo dos Problemas}

No contexto temporal da análise aqui apresentada, a prevalência de HIV/AIDS em Moçambique na população com idade entre 15 e 49 anos teve fases de grande ascendência. Em 1990, era cerca de $2 \%$ da população, em 2000 , de $12 \%$, e, em 2003 , de $14 \%$, revelando uma tendência à estabilidade entre 2004 e 2007, com uma taxa girando em torno de 16\%. Portanto, em 2001, no início dos diálogos entre Brasil e Moçambique para parcerias no combate ao HIV/AIDS, Moçambique vivia ainda um processo de aumento nos níveis de contágio (UNAIDS, 2020).

Além dos dados epidemiológicos do período, outro importante indicador se refere ao acesso aos antirretrovirais em Moçambique. Até o ano de 2001, o governo de Moçambique e os grandes contribuintes para a campanha nacional contra o HIV/AIDS mantinham uma 
posição oficial contrária à distribuição de antirretrovirais (ARV). Até esse período, o acesso ao ARV em Moçambique se dava apenas por meios privados ou por Organizações não Governamentais (ONGs). As ações do governo de Moçambique integradas pelo Plano Estratégico Nacional de Combate às DTS/HIV (PEN I), primeiro do tipo estabelecido em Moçambique, com vigência entre 2000 a 2002, não consideravam como possibilidade a distribuição pública de ARV (KULA, 2008).

A posição oficial do governo quanto à distribuição pública de ARV foi alterada com a aprovação do Diploma Ministerial n 183-A/2001, em 18 de dezembro de 2001, que regulamentou a introdução oficial da Terapia Antirretroviral (TARV) no país. A ação governamental teve início, mas, em 2003, ano da primeira visita do presidente Lula ao país, apenas 10 unidades sanitárias ofereciam TARV em 06 das 11 províncias do país. A introdução dos genéricos proporcionou redução dos custos e, consequentemente, aumento dos beneficiários, que, em outubro de 2004, chegaram a 7284 e, em 2005, a 19.000 (KULA, 2008).

Moçambique também possuía alta dependência externa para manter seus programas relacionados ao enfrentamento do HIV/AIDS. No país, cerca de $40 \%$ do orçamento era fruto de doações internacionais e $100 \%$ dos antirretrovirais distribuídos pelo governo também eram fruto de doações externas (FIOCRUZ, 2012). Além disso, 75\% do orçamento para a resposta nacional ao HIV/AIDS vinha de fontes internacionais (UNAIDS, 2013).

Outro ponto citado por Kingdon (1984) para o processo de conhecimento de uma situação é a ocorrência de eventos importantes como desastres, crises, experiência pessoal ou símbolos poderosos. Importantes eventos aos quais se pode fazer referência para a compreensão desse processo foram visitas diplomáticas estabelecidas entre Brasil e Moçambique, pois algumas delas se tornaram referência na formação da agenda que deu origem à parceria para a SMM.

A primeira visita importante foi a missão da Vice-Ministra da Saúde de Moçambique, Aída Libombo, ao Brasil entre os dias 21 e 24 de maio de 2001. Essa visita influenciou os acordos relativos à saúde firmados na visita do então presidente de Moçambique, Joaquim Alberto Chissano, que visitou o Brasil em 20 de julho de 2001, ocasião na qual foram assinados os primeiros atos internacionais entre Brasil e Moçambique relacionados à cooperação 
internacional em saúde e HIV/AIDS. Um desses atos foi o protocolo de intenções sobre cooperação técnica na área da saúde. Nesse documento, os países se comprometeram à prestação mútua de cooperação técnica em saúde em diversas áreas, nas quais se incluiu a transferência de tecnologia para a produção de antirretrovirais, mesmo antes da aprovação, em Moçambique, da distribuição pública de ARV (BRASIL; MOÇAMBIQUE, 2001a).

Também em 20 de julho de 2001, foi assinado um ajuste complementar ao acordo Geral de Cooperação assinado em 1981 pelos dois países. Esse ajuste dispôs sobre a implantação do projeto "Apoio ao Programa Nacional de Controle as DTS/SIDA" (BRASIL; MOÇAMBIQUE, 2001b). Com maior destaque nesse processo, e marco na formação dessa agenda, foi a visita do presidente Lula a Moçambique em novembro de 2003, quando o presidente brasileiro anunciou a intenção da participação brasileira na instalação da SMM.

Essas visitas foram consideradas como eventos de destaque que contribuíram para que - Brasil prestasse mais atenção na problemática de Moçambique e, portanto, elas são relevantes para a compreensão do fluxo dos problemas. A percepção de Puente (2010) de que as parcerias de cooperação técnica internacional brasileira são formadas a partir da demanda dos países receptores, da oferta brasileira e de uma agenda diplomática favorável contribui para o entendimento da importância dessas visitas para a formação da agenda.

Além da experiência pessoal dos governantes nas missões diplomáticas acima citadas, identificou-se a proximidade cultural entre os países como um símbolo poderoso para o conhecimento da situação. Brasil e Moçambique possuem um vínculo histórico por terem um colonizador em comum e compartilharem do mesmo idioma, fazendo, inclusive, parte da Comunidade de Países de Língua Oficial Portuguesa (CPLP).

No contexto-doméstico, desde 1996 é feita a distribuição gratuita de antirretrovirais no Brasil. Por conta da expertise adquirida em âmbito nacional, as ações relativas à prevenção e ao tratamento do HIV/AIDS ocuparam lugar de destaque na cooperação técnica brasileira. Contribuíram para isso um conjunto de fatores nacionais e internacionais que fizeram com que o Brasil fosse cada vez mais requisitado a participar de discussões internacionais a respeito do tema. Assim, o país passou a se destacar não só no âmbito da cooperação em HIV/AIDS, mas também como importante formador de opinião do tema. 
Em 2002, iniciou-se o primeiro programa brasileiro de grande amplitude de cooperação técnica internacional em HIV/AIDS. O Programa de Cooperação Internacional para Ações de Controle e Prevenção do HIV para Países em Desenvolvimento (PCI) lançou um processo seletivo internacional com a expectativa de atender dez países. Por meio de iniciativas com essa, o Brasil entrou no cenário internacional como um importante global player nas discussões sobre a doença, defendendo o acesso universal da população à prevenção, assistência e tratamento. Em 2004, o PCl passou ser chamado de "Projeto Laços Sul-Sul" (LIMA et al., 2010).

Após a influência dos indicadores e dos eventos de destaque para o reconhecimento de uma determinada situação, torna-se necessário identificar de que forma a situação percebida foi definida como um problema. Para Kingdon (1984), uma situação reconhecida passa a ser percebida como um problema quando se acredita que se precisa fazer algo para mudá-la. Uma situação passa a ser compreendida como um problema por comparação com a situação de outros países ou de outras unidades relevantes ou quando coloca em cheque valores importantes.

A unidade de análise mais relevante para essa comparação é a estabelecida entre Brasil e Moçambique referente a níveis epidemiológicos e acesso ao ART. Em 13 de novembro de 1996, o Brasil, com a aprovação da Lei $n^{\circ} 9.313$, foi o primeiro país em desenvolvimento a aprovar uma lei que assegurasse o acesso gratuito aos medicamentos antirretrovirais para pacientes portadores de HIV/AIDS. A aprovação desta lei e a política brasileira de atenção à saúde dos portadores de HIV/AIDS possibilitaram que, em 1998, 11 medicamentos antirretrovirais fossem distribuídos gratuitamente pela rede pública de saúde (AZEVEDO, 2010). O Brasil, em 2002, já era capaz de garantir tratamento a $100 \%$ dos doentes, provocando significativa diminuição nos índices de mortalidade (GRANGEIRO; SILVA; TEIXEIRA, 2009).

Uma situação também passa a ser definida como um problema quando coloca em xeque valores importantes e a necessidade de acesso universal a ARV sempre foi defendida pelo Brasil durante as negociações internacionais das quais o país fez parte. De acordo com Pedro Chequer, coordenador do programa das Nações Unidas de combate ao HIV/AIDS no Brasil, e Jorge Chediek, coordenador-residente do Sistema das Nações Unidas no Brasil, a 
partir de sua política nacional de combate ao HIV/AIDS, o Brasil era uma voz sempre presente nas discussões internacionais sobre o tema, contribuindo para o combate da doença também em outros países (UNAIDS, 2016).

Além disso, em 2001, o Brasil se opôs a exclusividade de comercialização e produção de ARV em um contencioso com os Estados Unidos (EUA) na Organização Mundial do Comércio (OMC). Os EUA questionaram a utilização brasileira da licença compulsória de medicamentos em casos de emergência de saúde pública, pois, para os EUA, esse licenciamento violaria o Acordo sobre Aspectos dos Direitos de Propriedade Intelectual relacionadas ao Comércio (OLIVEIRA; MORENO, 2007).

O governo brasileiro ameaçou, em 2001, conceder licença compulsória a dois antirretrovirais da empresa americana Merck e da suíça Roche. No entanto, ambas negociaram com o governo uma redução de $60 \%$ nos preços de seus medicamentos. Mesmo assim, o governo americano entrou com um pedido de consulta na OMC para questionar o direito brasileiro de conceder licença compulsória. Diante da mobilização brasileira internacional que, em conjunto com países menos desenvolvidos, chamou atenção para a relevância social do tema, os EUA decidiram retirar a queixa. O Brasil argumentava que o bem estar público deveria prevalecer sobre o lucro (OLIVEIRA; MORENO, 2007). O Quadro 1 sistematiza o fluxo dos problemas.

Quadro 1 - Fluxo dos Problemas

\begin{tabular}{|c|l|}
\hline $\begin{array}{c}\text { O que levou ao } \\
\text { conhecimento da } \\
\text { situação? }\end{array}$ & $\begin{array}{l}\text { Indicadores em Moçambique: Alta prevalência de soropositivos, baixo acesso aos } \\
\text { antirretrovirais e dependência externa no enfrentamento ao HIV/AIDS. }\end{array}$ \\
\cline { 2 - 2 } & $\begin{array}{l}\text { Eventos de destaque/símbolos poderosos: Visita ao Brasil da Vice-Ministra da Saúde } \\
\text { de Moçambique Aída Libombo, em maio de 2001, e do presidente Joaquim Chissano, } \\
\text { em junho de 2001. Visita do Presidente Lula a Moçambique em novembro de } 2003 . \\
\text { Proximidade cultural existente entre Brasil e Moçambique. }\end{array}$ \\
\hline $\begin{array}{c}\text { Sob quais bases a } \\
\text { situação foi } \\
\text { definida como um } \\
\text { problema? }\end{array}$ & Valores: O Brasil defendia nacional e internacionalmente o acesso a antirretrovirais. \\
\cline { 2 - 3 } & $\begin{array}{l}\text { Enquadramento: Discurso de reparação à África, mas com reconhecimento da } \\
\text { instrumentalidade da cooperação internacional para a Política Externa. }\end{array}$ \\
\hline
\end{tabular}

Fonte: Elaboração das autoras. 
Foi, portanto, possível identificar que o problema a ser atacado em Moçambique com a instalação da fábrica foi o baixo acesso aos antirretrovirais e a dependência externa que o país tinha para manter a distribuição pública desses medicamentos. Além disso, o acesso universal aos ARVs já era tema defendido nacional e internacionalmente pelo Brasil e a cooperação estabelecida com Moçambique era justificada por motivações humanitárias.

\section{Fluxo da Política}

A análise das ações que influenciaram o fluxo da política, fazendo ascender à agenda brasileira a questão do acesso aos ARVs em Moçambique, foi dividida em dois grandes blocos. O primeiro considerou as mudanças dentro do governo e o segundo levou em consideração o humor nacional. Para compreender como as mudanças no governo contribuíram para a formação da agenda diplomática brasileira com Moçambique no que diz respeito ao acesso aos ARVs, é relevante analisar o perfil da política externa e da Cooperação Técnica entre Países em Desenvolvimento (CTPD) dos governos que estiveram envolvidos nesse processo, especificadamente o governo do presidente Fernando Henrique Cardoso (1995-2002) e o primeiro governo do presidente Luiz Inácio Lula da Silva (2003-2006).

A diplomacia do governo Lula, de acordo com Almeida (2004), foi marcada por um ativismo exemplar, que pode ser comprovado pelas viagens e visitas bilaterais realizadas por Lula ou por seu Ministro das Relações Exteriores Celso Amorim, no Brasil e no exterior. No entanto, muitas dessas iniciativas seriam desdobramentos de ações iniciadas na administração do governo Fernando Henrique Cardoso (FHC). Mesmo nos casos em que tais iniciativas ganharam nova roupagem conceitual, elas estariam mais caracterizadas como de continuidade do que de ruptura. Em relação aos países africanos, em especial os lusófonos, FHC se limitava a um discurso de uma bem intencionada política de cooperação, enquanto Lula passou a proclamar uma ativa política de solidariedade com a África. Almeida (2004, p. 177) traduz a diplomacia FHC em "aceitar o mundo como ele é" e a de Lula em "mudar o mundo".

Para compreender como as mudanças no governo contribuíram para a formação da agenda diplomática do Brasil e de Moçambique no que tange ao acesso aos ARVs, torna-se 
necessário conhecer o perfil da política externa e da Cooperação Técnica entre Países em Desenvolvimento (CTPD) ${ }^{3}$ dos governos envolvidos nesse processo. Considerou-se o governo FHC (1995-2002) e o primeiro governo Lula (2003-2006), sendo este último responsável por consolidar a agenda em análise. Cabe destacar que o segundo mandato do governo Lula será considerado apenas em relação à seleção das alternativas.

Foram consideradas as mudanças relativas à CTPD nos dois governos, no plano do discurso e prático, para identificar como tais mudanças influíram na formação e na intensificação da agenda em questão. Um estudo realizado por Puente (2010) revelou como a CTPD era tratada no discurso de política externa e na prática diplomática do Governo FHC e do primeiro governo Lula. No plano do discurso, durante o governo FHC (1995-2002), a CTPD era pouco citada no discurso e nos documentos referentes à política externa. Nesses discursos e documentos, divulgados pelo próprio presidente e por seus chanceleres, Luiz Felipe Lampreia e Celso Lafer, se fazia maior referência à cooperação em sentido explícito apenas no que se refere aos países africanos, aos Países de Língua Oficial Portuguesa (CPLP) e aos Países Africanos de Língua Oficial Portuguesa (PALOP), com clara prioridade aos PALOP (PUENTE, 2010).

O combate ao HIV/AIDS estava entre as três temáticas de CTPD mais recorrentes no discurso de política externa do governo FHC. Para Puente (2010), mesmo tendo havido crescimento das ações de CTPD durante o governo FHC, com aumento de escopo, amplitude geográfica e áreas temáticas, esse aumento não se refletiu no discurso, em decorrência de uma percepção restrita acerca da instrumentalidade das ações de cooperação para a política

\footnotetext{
${ }^{3}$ O conceito de Cooperação Técnica entre Países em Desenvolvimento (CTPD) foi criado pelas Nações Unidas na década de 1970. Essa modalidade de cooperação está inserida no fenômeno da Cooperação Internacional. A CTPD se configurou como uma estratégia alternativa e complementar à cooperação tradicional estabelecida entre os países doadores do Norte e os países receptores do Sul. A Conferência das Nações Unidas sobre Cooperação entre Países em Desenvolvimento, realizada em Buenos Aires, em 1978, foi um marco para a formação da CTPD. Essa conferência foi o primeiro esforço coletivo de identificar e sistematizar formas, possibilidades e modalidades de CTPD (PUENTE, 2010). O Plano de Ação de Buenos Aires, documento resultante dessa conferência, estabeleceu o principal quadro referencial de cooperação técnica entre países em desenvolvimento. Ele lançou as bases para a disseminação da CTPD e tratava da necessidade de os países em desenvolvimento registrarem e partilharem informações sobre suas capacidades técnicas e experiências; estabelecerem e fortalecerem ligações institucionais e físicas necessárias para o compartilhamento de recursos; identificarem e concretizarem oportunidades de cooperação, com foco nas necessidades dos países menos desenvolvidos (UNDP, 2004).
} 
externa do país. Durante o primeiro mandato do governo Lula, a CTPD esteve mais presente no discurso de política externa, em comparação ao governo FHC, embora ainda sem presença muito expressiva. Houve também uma mudança no modo como esse tipo de ação passou a ser tratada no discurso, pois, no governo Lula, as ações de CTPD passaram a ser admitidas de modo mais claro como instrumentos de política externa.

A CTPD do Brasil com a África manteve seu peso no discurso de Política Externa do governo Lula assim como no governo FHC; no entanto, o governo Lula adicionou motivações solidárias e éticas de reparação pelo período de escravidão no seu discurso (BRASIL, 2007). Os discursos no governo Lula também ressaltavam a cooperação com países da CPLP, inclusive Moçambique, exemplificado por um trecho do discurso de posse de Celso Amorim, em $1^{\circ}$ de janeiro de 2003: “Angola e Moçambique, que passaram por prolongados conflitos internos, receberão atenção especial. Valorizaremos a cooperação no âmbito da CPLP [...]" (BRASIL, 2007, p. 17).

O combate ao HIV/AIDS no governo Lula, assim como no anterior, é um dos temas que mais receberam prioridade no discurso referente à cooperação do governo, atrás apenas da luta internacional contra a fome e a pobreza. No entanto, o aumento do peso no discurso não refletiu em ações concretas, pois mesmo com o aumento da demanda e reforço orçamentário da Agência Brasileira de Cooperação $(A B C)$ iniciada no último ano de mandato do $F H C$, as dificuldades institucionais da $A B C$, sobretudo no que se referem aos recursos humanos e operacionais, que foram amenizados apenas em 2005, dificultaram o aumento dessas ações (PUENTE, 2010).

De acordo com Lima (2005), no Brasil, o relativo desinteresse da opinião pública em geral, no que se refere às questões de política externa, assegura grande autonomia decisória ao Ministério das Relações Exteriores (MRE). A política externa também sofre insulamento no jogo legislativo por conta do princípio constitucional que dá ao Executivo a competência na condução da política externa. A escassa disputa entre forças partidárias pelo posto do Ministério das Relações Exteriores parece confirmar o dito popular de que política externa não rende votos. 
Para Puente (2010), o entrelaçamento das questões internas e externas tem aumentado a presença de temas de política internacional na mídia e no debate popular. Para o autor, por envolver recursos públicos destinados a outros países, seria importante que a CTPD contasse com maior participação e respaldo social. Mesmo não tendo sido identificados estudos a respeito da posição da opinião pública em geral acerca da cooperação internacional prestada pelo Brasil, há uma boa vontade do congresso em aprovar atos sobre o assunto. Isso pode ser percebido na aprovação das legislações referentes à implantação da SMM e das legislações anteriores relacionadas ao tema com Moçambique. Embora o poder legislativo tenha importante papel na seleção das alternativas por ter que ratificar tratados internacionais, a formação da agenda diplomática se refere diretamente à condução da política externa que, segundo a Constituição de 1988, é atribuída ao poder Executivo. Essa característica reduz a possibilidade de o tema ser alvo de debate pelas forças políticas, grupos de pressão e debate popular.

Mas, mesmo diante da estrutura brasileira de condução de política externa, ainda se pode considerar o "humor" de alguns personagens envolvidos nesse processo. Souza (2002) realizou, entre 2000 e 2001, uma pesquisa com 149 personalidades que formam a "comunidade brasileira de política externa" com questões sobre a agenda governamental de política externa do Brasil. Essa "comunidade" incluía autoridades governamentais, congressistas, empresários, representantes de grupos de interesse, líderes de organizações não governamentais, acadêmicos e jornalistas.

Para 99\% dos entrevistados, o Brasil deveria se envolver mais em questões internacionais, exercendo uma liderança que fosse compatível com seu grande território e tradição diplomática. Quando perguntada a opinião dos entrevistados sobre a concessão de ajuda econômica a países pobres, $80 \%$ dos entrevistados se mostraram favoráveis à iniciativa, mas, para a maioria deles, essa ajuda deve ser destinada aos países com os quais o Brasil tem vínculos históricos ou de língua, o que colocaria Moçambique na lista de países cuja cooperação seria defendida por essa "comunidade".

Quadro 2 - Fluxo da Política 


\begin{tabular}{|c|l|}
\hline \multirow{2}{*}{$\begin{array}{c}\text { Mudanças no } \\
\text { governo }\end{array}$} & $\begin{array}{l}\text { Fernando Henrique Cardoso (FHC): Multilateralismo moderado, prioridades } \\
\text { econômicas e discurso mais moderado de cooperação com a África. }\end{array}$ \\
\cline { 2 - 3 } Humor nacional & $\begin{array}{l}\text { Luiz Inácio Lula da Silva (LULA): Forte multilateralismo, prioridades políticas e } \\
\text { discurso que proclamava uma ativa política de solidariedade com a África. }\end{array}$ \\
\hline $\begin{array}{l}\text { A Comunidade brasileira de política externa se mostrava favorável às parcerias de } \\
\text { cooperação do Brasil com países com os quais possui vínculos históricos ou de } \\
\text { língua. Boa vontade do congresso em aprovar atos internacionais relativos à } \\
\text { cooperação internacional. }\end{array}$ \\
\hline
\end{tabular}

Fonte: Elaboração das autoras.

Portanto, embora a opinião pública não estivesse muito envolvida com a formação dessa agenda, pode-se dizer que a opinião dos atores envolvidos com questões de política externa, no período, tendia a ser favorável às parcerias de cooperação com países africanos de idioma português, como é o caso de Moçambique. O Quadro 2 destaca os principais pontos relativos ao fluxo da política.

Assim, considera-se que, no fluxo da política, a formação da agenda foi influenciada pela postura do governo FHC de aproximação com a África, em especial com os PALOP, e de cooperação em temas de HIV/AIDS. Essa postura foi intensificada pelo governo Lula por meio de uma ativa política de solidariedade com o continente. Além disso, o humor nacional favorável garantiu um terreno fértil para o desenvolvimento da agenda.

\section{Fluxo da Alternativa}

O processo de harmonização da política ocorreu no caso da SMM à medida que ela foi precedida por outras parcerias entre Brasil e Moçambique na área de saúde e HIV/AIDS. O primeiro ato internacional firmado entre os dois países na área da saúde foi um protocolo de intenções de cooperação técnica, firmado em julho de 2001, na ocasião da visita do então presidente de Moçambique ao Brasil. A assinatura desse protocolo foi precedida e balizada pelas negociações ocorridas com a visita da Vice-ministra da saúde de Moçambique ao Brasil, em maio de 2001. Um dos temas englobados por esse protocolo de intenções foi a transferência de tecnologia no âmbito da produção de antirretrovirais (BRASIL; MOÇAMBIQUE 2001a). 
Na mesma data, Brasil e Moçambique também firmaram um acordo para a implementação do projeto "Apoio ao Programa Nacional de Controle às DST/SIDA". Esse foi o primeiro acordo bilateral firmado entre os dois países para implantação de um projeto de cooperação relativo à doença. $O$ objetivo da parceria era o de fortalecer a capacidade técnica e gerencial do programa de controle das DSTs e HIV/AIDS de Moçambique (BRASIL; MOÇAMBIQUE, 2001b).

Em maio 2003, foi firmado um memorando de entendimento entre os países para a implementação do "Projeto de Assistência de Prevenção ao HIV/AIDS". Esse memorando foi firmado no âmbito do "Programa de Cooperação Internacional para Ações de Controle e Prevenção do HIV para Países em Desenvolvimento". O memorando previa o apoio a um projeto piloto para o tratamento de cerca de 100 pessoas com ARVs genéricos produzidos no Brasil e fornecidos pelo Ministério da Saúde a Moçambique (BRASIL; MOÇAMBIQUE, 2003a). O objetivo da implantação desse projeto seria estimular Moçambique a adotar uma política de assistência aos pacientes de HIV/AIDS, semelhante à aplicada no Brasil, promovendo o acesso aos medicamentos (TORRONTEGUY, 2010).

Considerando essas ações como importantes no processo de amaciamento da política, a análise de viabilidade começou a ser realizada em junho de 2003. Foi nesse período que a Fiocruz empreendeu uma visita a Moçambique a fim de analisar a situação do país para estabelecer uma proposta de cooperação. Em novembro de 2003, o processo de amaciamento construído a partir da visita da Vice-Ministra da Saúde de Moçambique ao Brasil em maio de 2001, dos primeiros acordos relativos ao HIV/AIDS firmados entre os países em junho de 2001 e do estudo de viabilidade empreendido pela Fiocruz em junho de 2003 deu origem a um protocolo de intenções para cooperação científica e tecnológica na área da saúde.

Em princípio, o protocolo de intenções previa que, ao Brasil, caberia oferecer apenas a formação necessária para o pessoal técnico que iria trabalhar na produção dos medicamentos e no gerenciamento do laboratório, cuja instalação, de acordo com o documento, era responsabilidade de Moçambique. O Brasil também ajudaria Moçambique na identificação do local para a instalação da fábrica. A infraestrutura física deveria ser disponibilizada por Moçambique, mas os países se comprometeram a buscar em conjunto os 
recursos financeiros necessários para a instalação do laboratório (BRASIL; MOÇAMBIQUE, 2003b). Portanto, em princípio, não estava previsto que o Brasil seria responsável pela doação dos equipamentos necessários para a instalação da fábrica.

Na mesma data da assinatura do protocolo, Brasil e Moçambique firmaram um ajuste complementar ao Acordo Geral de Cooperação de 1981, para a implementação do Projeto $\mathrm{PCl}-\mathrm{Ntwanano}$ em Moçambique. O projeto $\mathrm{PCl}-\mathrm{N}$ twanano visava fortalecer a capacidade gerencial do "Projeto de Assistência de Prevenção do HIV/AIDS" criado pelo memorando de 02 de maio de 2003, bem como fortalecer a cooperação técnica estabelecida entre Brasil e Moçambique na área de HIV/AIDS. Conforme dispôs o ajuste, caberia ao Brasil, dentre outros, o envio de especialistas a Moçambique, a realização de treinamentos e o envio de medicamentos genéricos antirretrovirais. A gestão e a avaliação dos projetos seriam responsabilidade de ambos os países (BRASIL; MOÇAMBIQUE, 2003c).

Em visita do presidente Moçambicano, Joaquim Alberto Chissano, ao Brasil, entre os dias 31 de agosto e 3 de setembro de 2004, o presidente Lula assumiu o compromisso de ser o Brasil o responsável por arcar com todos os custos decorrentes do estudo de viabilidade para a implementação da fábrica. Em 15 de julho de 2005 foi firmado ajuste complementar entre os países para a implementação do projeto "Estudo de viabilidade técnico econômico para a instalação de fábrica de medicamentos em Moçambique para produção de medicamentos antirretrovirais e outros" (BRASIL; MOÇAMBIQUE, 2005).

Conjuntamente com a assinatura do ajuste, também foi assinado o projeto do estudo de viabilidade. O custo do projeto de viabilidade foi orçado em US\$ 455.400 .00 e teria como fonte de financiamento o governo brasileiro, por meio do orçamento da Agência Brasileira de Cooperação $(A B C)$. Com o término do projeto, esperava-se que o estudo pudesse indicar a necessidade, a oportunidade e a viabilidade da construção da fábrica. Caso positivo, o estudo deveria também apontar seus custos aproximados, as fontes de matéria-prima e insumos e as fontes de recursos humanos. Caso não fosse determinada a viabilidade da fábrica, o estudo objetivava apontar alternativas para reduzir os fatores que provocavam a demanda por medicamentos, promovendo, por exemplo, programas de prevenção (BRASIL; MOÇAMBIQUE, 2005). 
O estudo de viabilidade foi dividido em três grandes fases. Na primeira, seria realizado o levantamento das condições pré-existentes em Moçambique, relativas à construção da fábrica. Nessa fase, seriam realizados levantamentos como, por exemplo, da capacidade de gastos do governo moçambicano em saúde, do quantitativo de pessoal envolvido no diagnóstico e tratamento do HIV/AIDS, dos recursos físicos disponíveis para esse diagnóstico e tratamento, da realidade quantitativa e qualitativa da atual oferta de medicamentos e as fontes desse fornecimento.

Na segunda etapa seria avaliada a alternativa de produção local dos medicamentos. Nessa fase, seriam realizados estudos como os de alternativas de produção local, os de custo de maquinário, de perfil e quantidade de pessoal necessário para fábrica, disponibilidade atual de pessoal qualificado para a fábrica bem como a necessidade de capacitação. Na terceira e última fase seria realizada a análise geral da viabilidade econômica e discutida com autoridades locais as alternativas estudadas (BRASIL; MOÇAMBIQUE, 2005).

Em 22 de agosto de 2007, o porta-voz do governo moçambicano, Luís Covane, anunciou, em Maputo, que o governou havia aprovado a instalação da fábrica de antirretrovirais no país. De acordo com ele, o estudo de viabilidade realizado pelo Brasil indicava que Moçambique precisava da fábrica. O estudo de viabilidade foi apresentado ao Ministro da Saúde de Moçambique, Ivo Garrido, em maio de 2007. Em 2008, Moçambique adquiriu a única indústria farmacêutica existente em Moçambique, uma fábrica de soros, para a instalação da SMM (FIOCRUZ, 2012).

Em 04 de setembro de 2008 foram firmados entre Brasil e Moçambique um ajuste complementar para "Capacitação em Produção de Medicamentos antirretrovirais e outros medicamentos". O objetivo deste ajuste foi o de implementar um projeto de capacitação aos profissionais de Moçambique para atuarem na produção dos medicamentos da fábrica, cuja análise de viabilidade já havia sido concluída. Essa capacitação envolveria não só a produção de medicamentos, mas também gestão e administração da indústria farmacêutica, garantia da qualidade e manutenção da indústria. Nesse processo, a $A B C$ atuaria como instituição responsável pela coordenação, acompanhamento e avaliação do projeto e o Instituto de 
Tecnologia de Fármacos (Farmanguinhos) foi designado como instituição executora (BRASIL; MOÇAMBIQUE, 2008a).

Outro ajuste firmado em 04 de setembro de 2008 foi para o "Fortalecimento institucional do Órgão Regulador de Medicamentos de Moçambique como agente regulador do setor farmacêutico". Esse ajuste tinha por objetivo fortalecer o Órgão Regulador de Medicamentos de Moçambique, por meio de capacitação e troca de experiência com a Agência Nacional de Vigilância Sanitária (Anvisa). A instituição brasileira responsável pela execução das atividades desse ajuste foi a Anvisa e, por parte de Moçambique, foi designado o Órgão Regulador de Medicamentos de Moçambique (BRASIL; MOÇAMBIQUE, 2008b).

Na mesma data dos ajustes foi assinado um acordo entre os governos para a instalação da sede do escritório regional da Fiocruz para a África. Este acordo previa a instalação do escritório da Fiocruz África em Maputo, Moçambique. O objetivo desse escritório seria o de coordenar, acompanhar e avaliar os programas de cooperação em saúde entre a Fiocruz e os países africanos, inclusive os estabelecidos com Moçambique para a construção da fábrica. Este escritório, conforme previa o acordo, gozaria de imunidade e inviolabilidade, possuindo personalidade jurídica internacional (BRASIL; MOÇAMBIQUE, 2008c).

Em 14 de dezembro de 2009, foi aprovada, no Brasil, a Lei $n^{\circ} 12.117$, que autorizou o Poder Executivo brasileiro a doar recursos a Moçambique, no total de até RS\$13.600.000,00 para auxiliar na construção da primeira fase da fábrica de medicamentos. Essa doação foi feita com base no orçamento do Ministério da Saúde. O processo de aprovação desta lei teve início em 2008, com sua proposição feita pelo Poder Executivo. De acordo com a exposição de motivos do projeto de lei, apresentada em $1^{\circ}$ de outubro de 2008 , o recurso doado pretendia financiar a instalação da primeira fase da fábrica e seria destinado às obras de instalação e para aquisição de equipamentos, utensílios e insumos para medicamentos. A doação foi justificada pela importância estratégia e humanitária dessa parceria para o Brasil (BRASIL, 2009).

$\mathrm{Na}$ exposição de motivos foi apresentado o quadro epidemiológico de Moçambique, onde, de acordo com o documento, $87 \%$ da população que necessitava de tratamento com antirretrovirais não tinham acesso aos medicamentos. A defesa da aprovação da doação 
também foi defendida com o objetivo de impedir a apropriação do projeto de construção da fábrica por outros países, o que, de acordo com o documento, representaria a perda de um valioso instrumento de cooperação e de afirmação dos interesses políticos brasileiros na África (BRASIL, 2008). Para Hayne Silva, diretor de Farmanguinhos, um dos impasses para a instalação da fábrica era que não estava prevista, na legislação brasileira, a doação de equipamentos, por isso o presidente Lula enviou ao congresso o projeto de Lei para a liberação dos R\$13,6 milhões destinados à aquisição do maquinário (SILVA; SPÉCIE; VITALE, 2010).

Entre os dias 9 e 10 de novembro de 2010, o presidente Lula realizou sua terceira viagem a Moçambique, ocasião na qual inaugurou a primeira fase da fábrica de medicamentos (UCHÔA, 2010). Em 22 de dezembro de 2011 foi assinado, em Maputo, pelo embaixador do Brasil em Maputo e pelo Ministro da Saúde de Moçambique, um ajuste complementar ao acordo de cooperação estabelecido entre os dois países em 1981 para o "Projeto de instalação da fábrica de antirretrovirais e outros medicamentos em Moçambique”. Seu objetivo seria o de implementar o projeto de instalação da fábrica por meio da transferência de conhecimentos, tecnologia e capacitação de recursos humanos moçambicanos. O documento considerou a conclusão da análise de viabilidade da fábrica, prevista no ajuste firmado em 15 de julho de 2005 (BRASIL; MOÇAMBIQUE, 2011).

O ajuste de 22 de dezembro de 2011 marca, para nosso artigo, o fim da fase de seleção de alternativas que deu origem à fábrica, uma vez que foi por meio desse documento que ficou oficializada a parceria dos países para a instalação da SMM. O documento previu que os equipamentos para a fábrica seriam adquiridos pelo Brasil por meio do Farmanguinhos/Fiocruz e doados ao Ministério da Saúde de Moçambique. A Moçambique também caberia, entre outros, a coordenação do projeto e a disponibilização e manutenção das instalações necessárias para a produção dos medicamentos, atendendo às normas estabelecidas pela Agência Reguladora Nacional e pelas Agências Internacionais (BRASIL; MOÇAMBIQUE, 2011).

De acordo com uma nota informativa publicada pela Fiocruz, a iniciativa de instalação da fábrica tinha por objetivo fundamental criar condições para que existisse em Moçambique uma indústria farmacêutica pública, com capital 100\% pertencente ao governo moçambicano, 
sustentável, capaz de produzir antirretrovirais e outros medicamentos voltados para a atenção básica à saúde, reduzindo a dependência de doações internacionais e criando em Moçambique competências tecnológicas e de gestão industrial farmacêutica. Para tanto, o Brasil realizaria a transferência de tecnologia de produção de 21 medicamentos, 6 deles antirretrovirais. Também contribuiria com a elaboração da documentação necessária para a obtenção das certificações necessárias junto às autoridades reguladoras (FIOCRUZ, 2012).

No que diz respeito à importância da comunidade de especialistas, ou participantes invisíveis, como geradores e difusores de alternativas de políticas públicas, embora a política externa brasileira fosse conduzida pelo executivo, diminuindo as possibilidades de debates públicos para sua definição, o poder executivo conta com um corpo diplomático, ou seja, uma comunidade de especialistas que apoia esse processo. No caso da SMM, os participantes invisíveis tiveram papel fundamental na dinâmica dessa política por meio da atuação dos técnicos da Fiocruz e da $A B C$ na realização dos estudos de viabilidade. Foi com base nesses estudos que a escolha da política pública foi realizada pelos participantes visíveis.

As obras da fábrica foram concluídas em fevereiro de 2012 e a operação fabril teve início em 22 de julho do mesmo ano, sem que a totalidade da área de produção estivesse em operação. Nesta data teve início a embalagem do medicamento Nevirapina. Esse medicamento era produzido pelo Brasil e enviado a Moçambique apenas para ser embalado (FIOCRUZ, 2012). Entre julho e setembro de 2013, a fábrica produziu seus primeiros medicamentos, todos para hipertensão. Em agosto de 2013, a fábrica produziu pela primeira vez um medicamento antirretroviral genérico, a Lamivudina e, em agosto de 2013, produziu seu segundo antirretroviral, a Nevirapina. No entanto, os medicamentos ainda precisavam obter o certificado de qualidade do órgão regulador de medicamentos de Moçambique, mas, enquanto isso, a fábrica começou a embalar um antibiótico e um antirretroviral enviados pelo Brasil.

Nesse cenário, o questionamento recorrente é se haveria orçamento para manter a fábrica em funcionamento. O projeto foi criado com a expectativa de que a produção excederia a necessidade de Moçambique e esse excesso poderia ser vendido a outros países do sul da África, e a renda dessas vendas manteria o funcionamento da fábrica. No entanto, 
não era possível prever, naquele momento, se os medicamentos produzidos pela SMM teriam preços competitivos o suficiente para concorrer com os fornecedores de medicamentos do sul da África, entre eles, o principal fornecedor, a Índia, que, por seus baixos preços, era uma das principais fornecedoras de medicamentos do mundo. O Quadro 3 sintetiza os principais pontos identificados no fluxo da alternativa.

Quadro 3 - Fluxo das Alternativas

\begin{tabular}{|c|c|}
\hline \multirow{3}{*}{$\begin{array}{l}\text { Dinâmica das políticas } \\
\text { públicas }\end{array}$} & $\begin{array}{l}\text { Amaciamento da política por meio de parcerias entre Brasil e Moçambique } \\
\text { relativas à saúde e HIV/AIDS anteriores a } 2003 \text {. }\end{array}$ \\
\hline & $\begin{array}{l}\text { Avaliação inicial para o estabelecimento da proposta realizada pela Fiocruz em } \\
\text { junho de } 2003 .\end{array}$ \\
\hline & $\begin{array}{l}\text { Análise de viabilidade técnica desenvolvida pela ABC em } 2005 \text { e aprovada pelo } \\
\text { governo de Moçambique em agosto de } 2007 \text {. }\end{array}$ \\
\hline $\begin{array}{l}\text { Comunidade de } \\
\text { especialistas como } \\
\text { difusores da política } \\
\text { pública? }\end{array}$ & $\begin{array}{l}\text { A Fiocruz e a } A B C \text { exerceram papel de destaque na produção de alternativas por } \\
\text { meio da realização de estudos de viabilidade; no entanto, a seleção das } \\
\text { alternativas que seriam aplicadas foi realizada pelos participantes visíveis. }\end{array}$ \\
\hline
\end{tabular}

Fonte: Elaboração das autoras.

As parcerias na área da saúde e HIV/AIDS, estabelecidas entre Brasil e Moçambique anteriores à SMM, foram relevantes, segundo o modelo de Kingdon (1984), à medida que "amaciaram" o terreno para a criação da SMM. Ademais, a produção da alternativa da SMM teve a participação dos chamados "atores invisíveis" por meio das análises de viabilidade realizadas pela Fiocruz e pela ABC. Embora Kingdon (1984) trate os "atores invisíveis" organizados em comunidades de especialistas como importantes difusores de propostas de políticas públicas, no caso da SMM, a difusão também foi realizada, em grande parte, pelo então presidente Lula, considerado um "ator visível", e por sua equipe diplomática, em consequência do modelo de condução da política externa brasileira.

\section{CONSIDERAÇÕES FINAIS}

Com base no modelo de Kingdon (1984), identificou-se os fluxos que deram origem à agenda e à alternativa de política pública para a participação do Brasil na instalação da Sociedade Moçambicana de Medicamentos (SMM). Constata-se que a agenda teve início efetivo no governo Luiz Inácio Lula da Silva, mas sua ascensão só foi possível diante da 
condução da política externa do governo Fernando Henrique Cardoso (FHC). De acordo com Puente (2010), o Brasil tende a cooperar quando a demanda dos países receptores se relaciona com a oferta do Brasil e essa oferta, em geral, está ligada às áreas em que o Brasil possui experiência acumulada e até níveis de excelência. Esse foi o caso da SMM, relacionada à expertise do Brasil no combate e controle do HIV/AIDS.

Do ponto de vista estratégico, a demanda tem um peso importante nas ações de Cooperação Técnica entre Países em Desenvolvimento (CTPD) do Brasil, revelando assim sua predisposição à horizontalidade; além disso, as circunstâncias da agenda diplomática são relevantes na definição das ações de cooperação. A visita de um presidente ou Chanceler a um país pode exercer grande influência na escolha de um receptor e da temática da cooperação. Embora a instrumentalidade política das ações de cooperação internacional do Brasil no governo Lula tenha sido abertamente declarada, o Brasil não induz a demanda dos países receptores com objetivo de obter ganhos comerciais. Isso acontece devido à falta de coordenação entre as ações de CTPD e a política de promoção comercial do Itamaraty. Assim, quando ocorrem ganhos comerciais, eles são eventuais e não são frutos de planos preestabelecidos (PUENTE, 2010).

A demanda desempenhou papel importante na parceria para a instalação da SMM, já que as solicitações de parceria partiram de Moçambique. Mas, percebe-se que a horizontalidade defendida pelo Brasil em suas parcerias de cooperação é difícil de ser efetivada em casos como o da SMM aonde há grande deficiência no país receptor. A falta de experiência de Moçambique no tema deixou a cargo do Brasil todo o processo de análise, estudos de viabilidade e produção de propostas. Portanto, embora no plano do discurso, o Brasil defenda parcerias de cooperação construídas em bases de igualdade, Moçambique permaneceu passivo diante da construção das alternativas para a instalação da SMM. É evidente que essa passividade de Moçambique está diretamente ligada com a falta de expertise do país na área de HIV/AIDS e com o histórico de dependência externa do país, que estava habituado a receber a cooperação de modo impositivo. A seleção da alternativa precisou passar pelo crivo moçambicano, pois carecia de sua aprovação; no entanto, as 
dificuldades institucionais do país provocaram dificuldades no processo de implantação da fábrica.

A partir do modelo dos fluxos múltiplos, foi possível compreender as variáveis envolvidas para, então, entender essa formação. A parceria poderia ser analisada sob a ótica de Puente (2010) de que a CTPD brasileira é formada pela junção de oferta, demanda e agenda diplomática favorável. Moçambique possuía alta demanda por ARVs e o Brasil um programa internacionalmente reconhecido em HIV/AIDS, o que poderia considerar como oferta, e as visitas estabelecidas entre os países criou uma agenda diplomática favorável. No entanto, a análise a partir do modelo de Kingdon (1984) nos permitiu considerar outras variáveis que garantem maior profundidade a nossa análise, considerando, inclusive, outras questões nacionais dos países envolvidos, conforme defende Lancaster (2007).

O Brasil, que começou a cooperar em HIV/AIDS no governo FHC, não destacava oficialmente a CTPD como um instrumento de política externa. Nesse mesmo período, Moçambique possuía altas taxas de infecção por HIV/AIDS, com alta dependência externa para o tratamento da doença e sem nenhum programa público de distribuição de ARVs. O governo Lula inaugurou uma política mais ativa em relação à África, admitidamente utilizada como instrumento de política externa, mas também justificada por motivações altruísticas e de proximidade histórica e cultural.

A situação de Moçambique foi percebida pelo Brasil como um problema com base nos indicadores epidemiológicos e de tratamento em HIV/AIDS, pelos feedbacks positivos de outras ações brasileiras relativas ao acesso aos ARVs, cuja importância já estava dentro dos valores defendidos pelo Brasil, tanto nacional quanto internacionalmente. Assim, o problema foi percebido pelo Brasil e também identificado no Fluxo dos Problemas de Kingdon, para a formação da agenda brasileira. Outro ponto importante para que essa agenda fosse formada foi o contexto da política ou o fluxo da política. Nesse sentido, analisa-se o contexto político brasileiro, identificam-se as mudanças de discurso e de ações do governo FHC e Lula, importantes para a formação dessa agenda, e o humor nacional brasileiro, favorável a esse tipo de iniciativa. Um fluxo político favorável, que no Brasil tinha um presidente que desejava 
implementar uma política ativa em relação à África, em parte justificada por seus auspícios em política externa, garantiu que o tema ascendesse à agenda.

Mas depois de percebido o problema, o que deveria ser feito a respeito? A ideia da instalação da fábrica passou por uma série de crivos próprios do fluxo das alternativas, estudos e análises de viabilidade, aprovação do país receptor etc. As etapas das políticas públicas nem sempre acontecem em sequência perfeita. Assim, sabe-se que muitas etapas envolvidas na seleção das alternativas acontecem concomitantemente à implantação do projeto. Considerase o fim da seleção das alternativas em 2011, quando o acordo final de implantação da fábrica foi assinado.

Com base nesses fluxos, tem-se então a janela de oportunidade, quando há a junção dos três fluxos considerados: o fluxo dos problemas, da política e das alternativas. Tem-se uma agenda formada, ou seja, o governo brasileiro considerava o problema de Moçambique, e uma alternativa, que após passar pelos crivos próprios, foi selecionada. Assim, foi instalada, em Moçambique, a Sociedade Moçambicana de Medicamentos (SMM), alvo de inúmeros debates, mas cuja necessidade e importância são incontestáveis.

\section{REFERÊNCIAS}

ALMEIDA, Paulo Roberto. Uma política externa engajada: a diplomacia do governo Lula. Revista Brasileira de Política Internacional, Brasília, v. 47, n. 1, p. 162-184, 2004.

AZEVEDO, Maria Gabriela da Silva Lopes e Carravilla. Acesso gratuito a medicamentos Antirretrovirais: Contribuição do Legislativo para a Política de Combate à AIDS no Brasil. 2010. Monografia (Especialização em Legislativo e Políticas Públicas) - Centro de Formação, Treinamento e Aperfeiçoamento da Câmara dos Deputados (Cefor), Brasília, 2010.

BRASIL. Programa de Cooperação Internacional para Ações de Prevenção e Controle do HIV/Aids para outros Países em Desenvolvimento. Brasília: Ministério da Saúde, 2002.

BRASIL. Política Externa Brasileira. Vol. I: Discursos, artigos e entrevistas do Presidente Luiz Inácio Lula da Silva (2003-2006). Brasília: Ministério das Relações Exteriores, 2007.

BRASIL. Exposição de Motivos Interministerial no 00021/MS/MRE. Brasília: MS/MRE, 1으 out. 2008. Disponível em: 
https://www.camara.leg.br/proposicoesWeb/prop_mostrarintegra?codteor=604743\&filena $m e=P L+4145 / 2008$. Acesso em: 30 out. 2020.

BRASIL. Lei $n^{\circ}$ 12.117, de 14 de dezembro de 2009. Autoriza a União a doar recursos a República de Moçambique para a primeira fase de instalação de fábrica de antirretrovirais e outros medicamentos. Diário Oficial da União: Seção 1, Brasília, DF, p. 11, 5 de dezembro de 2009.

BRASIL; MOÇAMBIQUE. Protocolo de intenções entre o Governo da República Federativa do Brasil e o Governo da República de Moçambique sobre Cooperação Técnica na área da Saúde. Brasília: Governo da República Federativa do Brasil/Governo da República de Moçambique, 2001a.

BRASIL; MOÇAMBIQUE. Ajuste complementar ao Acordo Geral de Cooperação entre o governo da República Federativa do Brasil e o governo da República de Moçambique para implementação do projeto "Apoio ao Programa Nacional de Controle às DST/SIDA". Brasília: Governo da República Federativa do Brasil/Governo da República de Moçambique, 2001b.

BRASIL; MOÇAMBIQUE. Memorandum de entendimento entre o governo da República Federativa do Brasil e o governo da República de Moçambique no âmbito do Programa de Cooperação Internacional do Ministério da Saúde do Brasil. Maputo: Governo da República Federativa do Brasil/Governo da República de Moçambique, 2003a.

BRASIL; MOÇAMBIQUE. Protocolo de intenções entre o Governo da República Federativa do Brasil e o governo da República de Moçambique sobre Cooperação Científica e Tecnológica na área da saúde. Maputo: Governo da República Federativa do Brasil/Governo da República de Moçambique, 2003b.

BRASIL; MOÇAMBIQUE. Ajuste complementar ao Acordo Geral de Cooperação entre governo da República Federativa do Brasil e governo da República de Moçambique para implementação do projeto PCI-NTWANANO no âmbito do Programa de Cooperação Internacional do Ministério da Saúde do Brasil. Maputo: Governo da República Federativa do Brasil/Governo da República de Moçambique, 2003c.

BRASIL; MOÇAMBIQUE. Ajuste complementar ao Acordo Geral de Cooperação entre o governo da República Federativa do Brasil e o governo da República de Moçambique para implementação do projeto "Estudo de Viabilidade técnico econômico para a instalação de fábrica de medicamentos em Moçambique para produção de medicamentos antirretrovirais e outros". Maputo: Governo da República Federativa do Brasil/Governo da República de Moçambique, 2005. 
BRASIL; MOÇAMBIQUE. Ajuste complementar ao Acordo Geral de Cooperação entre o governo da República Federativa do Brasil e o governo da República de Moçambique para implementação do projeto "Capacitação para produção de medicamentos antirretrovirais e outros medicamentos". Brasília: Governo da República Federativa do Brasil/Governo da República de Moçambique, 2008a.

BRASIL; MOÇAMBIQUE. Ajuste complementar ao Acordo Geral de Cooperação entre o governo da República Federativa do Brasil e o governo da República de Moçambique para implementação do projeto "Fortalecimento institucional do órgão regulador de medicamentos de Moçambique como agente regulador do setor farmacêutico". Brasília: Governo da República Federativa do Brasil/Governo da República de Moçambique, 2008b.

BRASIL; MOÇAMBIQUE. Acordo entre a República Federativa do Brasil e o governo da República de Moçambique para instalação da sede do escritório regional da FIOCRUZ para a África. Brasília: Governo da República Federativa do Brasil/Governo da República de Moçambique, 2008c.

BRASIL; MOÇAMBIQUE. Ajuste complementar ao Acordo Geral de Cooperação entre o governo da República Federativa do Brasil e o governo da República de Moçambique para o projeto de instalação da fábrica de antirretrovirais e outros medicamentos em Moçambique. Maputo: Governo da República Federativa do Brasil/Governo da República de Moçambique, 2011.

COHEN, Michael D.; MARCH, James G., OLSEN, Johan P. A garbage can model of organizational choice. Administrative Science Quarterly, [Thousand Oaks, California], v. 17, n. 1, p. 1-25, 1972.

COMITIVA do governo brasileiro visita projetos de cooperação em Moçambique. Mundo Lusíada, 17 jan. 2020. Disponível em: https://www.mundolusiada.com.br/cplp/comitiva-dogoverno-brasileiro-visita-projetos-de-cooperacao-em-mocambique. Acesso em: 25 out. 2020.

FIOCRUZ - FUNDAÇÃO OSWALDO CRUZ. Cooperação Técnica entre Países em

Desenvolvimento Brasil / Moçambique - Sumário Executivo: Estudo de viabilidade técnicoeconômico para instalação da fábrica de medicamentos em Moçambique para produção de anti-retrovirais e outros. Brasília: Fiocruz, 2007.

FIOCRUZ - FUNDAÇÃO OSWALDO CRUZ. Nota informativa sobre a iniciativa de instalação da fábrica de antirretrovirais e outros medicamentos em Moçambique. Rio de Janeiro: Fiocruz, 2012. 
FOLLÉR, Maj-Lis. Cooperação Sul-Sul: A parceria brasileira com Moçambique e a construção de uma fábrica de medicamentos de combate à AIDS. Austral: Revista Brasileira de Estratégia e Relações Internacionais, Porto Alegre, v. 2, n. 3, p. 181-208, 2013.

GOVERNO de Moçambique aprova eventual construção de uma fábrica de medicamentos. MACAUHUB, 22 ago. 2017. Disponível em:

https://macauhub.com.mo/pt/2007/08/22/portugues-governo-de-mocambique-aprovaeventual-construcao-de-uma-fabrica-de-medicamentos. Acesso em: 24 out. 2020.

GRANGEIRO, Alexandre; SILVA, Lindinalva Laurindo; TEIXEIRA, Paulo Roberto. Resposta à AIDS no Brasil: contribuições dos movimentos sociais e da reforma sanitária. Revista Panamericana de Salud Publica, [Washington, D.C.], v. 26, n. 1, p. 87-94, 2009.

KINGDON, John Wells. Agenda, alternatives and public policy. Boston: Little Brown Publishing, 1984.

KULA. Análise da situação do HIV e SIDA e o acesso ao tratamento em Moçambique. Maputo: Kula, 2008.

LANCASTER, Carol. Foreign aid: diplomacy, development, domestic politics. Chicago: The University of Chicago Press, 2007.

LIMA, Maria Regina Soares de. A política externa brasileira e os desafios da cooperação SulSul. Revista Brasileira de Política Internacional, Brasília, v. 48, n. 1, p. 24-59, 2005.

LIMA, Thaísa Góis Santos; CAMPOS, Rodrigo Pires de. O perfil dos projetos de cooperação técnica brasileira em Aids no mundo: explorando potenciais hipóteses de estudo. Revista Eletrônica de Comunicação, Informação e Inovação em Saúde, Rio de Janeiro, v. 4, n. 1, p. 119-133, 2010.

MRE - MINISTÉRIO DAS RELAÇÕES EXTERIORES. Cooperação Técnica. Disponível em: http://www.itamaraty.gov.br/temas/cooperacao-tecnica. Acesso em: 10 jun. 2019.

OLIVEIRA, Marcelo Fernandes de; MORENO, Fernanda Venceslau. Negociações comerciais internacionais e democracia: o contencioso Brasil x EUA das patentes farmacêuticas na OMC. Dados - Revista de Ciências Sociais. Rio de Janeiro, v. 50, n. 1, p. 189-220, 2007.

PUENTE, Carlos Alfonso Iglesias. A cooperação técnica horizontal brasileira como instrumento de política externa: a evolução da cooperação técnica com países em desenvolvimento - CTPD - no período 1995-2005. Brasília: Fundação Alexandre Gusmão, 2010. 
ROSSI, Amanda. Depois de 10 anos, fábrica de remédios contra Aids começa a produzir na África. Estadão, 2 nov. 2013. Disponível em:

http://brasil.estadao.com.br/noticias/geral,depois-de-10-anos-fabrica-de-remedios-contraaids-comeca-a-produzir-na-africa,1092215. Acesso em: 9 nov. 2020.

ROSSI, Amanda. Em vez de remédio contra Aids, fábrica financiada pelo Brasil em Moçambique produzirá analgésico. BBC Brasil, 6 dez. 2017. Disponível em: http://www.bbc.com/portuguese/internacional-42176248. Acesso em: 9 nov. 2020.

SANCHES, Michelle Ratton; SILVA, Elaini Cristina Gonzaga da; CARDOSO, Evorah Lusci Costa; SPÉCIE, Priscila. Política externa como política pública: uma análise pela regulamentação constitucional brasileira (1967-1988). Revista de Sociologia Política, Curitiba, v. 27, p. 125143, nov. 2006.

SILVA, Elaini Cristina Gonzaga da; SPÉCIE, Priscila; VITALE, Denise. Atual arranjo institucional da política externa brasileira. Brasília, DF: IPEA, 2010. (Texto para discussão, n. 1489).

SOUZA, Amauri. A agenda internacional do Brasil: um estudo sobre a comunidade brasileira de política externa. Rio de Janeiro: Centro Brasileiro de Estudos Internacionais (CEBRI), 2002.

TORRONTEGUY, Marco Aurélio Antas. O Direito Humano à Saúde no Direito Internacional: Efetivação por meio da cooperação sanitária. 2010. Tese (Doutorado em Direito) - Faculdade de Direito, Universidade de São Paulo, São Paulo, 2010.

UCHÔA, Pablo. Lula se despede da África inaugurando fábrica de medicamentos. BBC News, 9 nov. 2010. Disponível em:

https://www.bbc.com/portuguese/noticias/2010/11/101109_mocambique_lula_terca_pu. Acesso em: 15 abr. 2020.

UNAIDS - JOINT UNITED NATIONS PROGRAMME ON HIV/AIDS. Global Report: UNAIDS report on the global AIDS epidemic 2013. Disponível em:

https://www.unaids.org/en/resources/documents/2013/20130923_UNAIDS_Global_Report _2013. Acesso em: 20 jan. 2020.

UNAIDS - PROGRAMA CONJUNTO DAS NAÇÕES UNIDAS SOBRE HIV/AIDS. Epidemia de VHI nos países de língua oficial portuguesa. Disponível em: http://www.aids.gov.br/pt$\mathrm{br} /$ pub/2018/epidemia-de-vih-nos-paises-de-lingua-oficial-portuguesa. Acesso em: 14 maio 2020.

UNAIDS - PROGRAMA CONJUNTO DAS NAÇÕES UNIDAS SOBRE HIV/AIDS. A ONU e a resposta à aids no Brasil. [2016]. Disponível em: https://unaids.org.br/wpcontent/uploads/2016/03/A-ONU-e-a-respostaPORTUGU\%C3\%8AS.pdf. Acesso em: 07 jul. 2020. 
UNDP - UNITED NATIONS DEVELOPMENT PROGRAMME. Forging a Global South. United Nations Day for South-South cooperation. 2004. Disponível em:

http://www.undp.org/content/dam/china/docs/Publications/UNDP-CH-PR-PublicationsUNDay-for-South-South-Cooperation.pdf. Acesso em: 12 nov. 2020. 